\title{
Evaluation of Bond Strength and Dimensional Accuracy of Soft Liner to Microwave Cured Denture Base Material
}

\author{
Shilan H. Fatah*, Radhwan H. Hasan \\ Department of Prosthodontics, College of Dentistry, Tishk International University, Erbil, Kurdistan Region, Iraq
}

\begin{abstract}
${ }^{*}$ Corresponding author: Shilan H. Fatah, Department of Prosthodontics, College of Dentistry, Tishk International University, Erbil, Kurdistan

Region, Iraq.

E-mail: shilan.aban@gmail. com
\end{abstract}

Received: 10 March 2020

Accepted: 20 May 2020

Published: 30 December 2020

DOI

10.25156/ptj.v10n2y2020.pp32-37

\section{A B S T R A C T}

Today, soft liners are being widely used in dental practices by their application to the inner surfaces of the denture with hopes to evenly distribute any potential uneven forces, and to provide a cushion effect to the oral mucosa of the patient mouth. The aim of this study is to investigate the influence of (a) polymethylmethacrylate (PMMA) denture base material curing technique, (b) Molloplast B soft liner curing technique, and (c) PMMA surface treatment, on the "shear bond strength" (SBS) between the Molloplast B liner and PMMA. A total of 80 samples were used in this study to evaluate the SBS performance of microwave (Nature-Cryl, Acron Gc, Japan) and conventional water bath (Ivoclar triplex, Liechtenstein) curing techniques of PMMA, and to evaluate the curing technique of soft liner material Molloplast B (DETAX,GERMANY). Surface treatment of PMMA was performed for half of the samples using neodymium:yttrium aluminum-garnet $\mathrm{Nd}$ :YAG laser, and the other half of the samples were surface-treated using $\mathrm{AL}_{2} \mathrm{O}_{3}$ sandblasting method. The results showed that the highest mean value in conventional water bath-cured soft liner was $26.69 \mathrm{MPa}$, whereas the lowest mean value for microwave-cured soft liner was 15.22 MPa. No significant difference was observed between the SBS performance regarding the PMMA surface treatment and curing techniques. Conventional water bath curing technique for soft liner treatment improved the SBS performance. Regarding the PMMA curing technique, the conventional water bath achieved higher SBS, yet the difference was not statistically significant. Finally, surface treatment using laser improved the SBS compared to sandblasted method, but the improvement here was also statistically insignificant.

Keywords: $\mathrm{AL}_{2} \mathrm{O}_{3}$ sandblasting; Nd:YAG laser; Polymethylmethacrylate; Shear bond strength; Soft liner

\section{INTRODUCTION}

Soft liner materials are being considered today by the dentistry practitioners as an answer to numerous clinical problems they are facing. It is believed they can help achieve an evened-out load distribution on the areas where the dentures are applying force, and distribute the stress concentrations (Tata and Nandeeshwar, 2012). Soft liner materials are frequently employed as a cushion material for the intaglio surfaces of dentures so that any mucosa trauma and bony undercuts can be prevented, and unwanted effects such as ridge atrophies, bruxism, and xerostomia (dry mouth) can be alleviated. Furthermore, they are believed to be helpful in edentulous arches that oppose natural dentition, and the congenital oral defects require obturation. These materials also enhance the retention of the dentures, (Akin et al., 2013). In case the adhesion between the lining material and the denture base fails, this may cause the oral environment to change in a way that may harbor bacterial growths. In addition, such an event may also accelerate the breakdown of the lining material used (Sauer, 1966). Therefore, it is important to maximize the strength of the bond between the soft liner and the denture base material. Several studies have investigated potential methods to achieve enhanced bond strength between the soft liner and the denture based material, which include the use of rough surfaces for polymethylmethacrylate (PMMA), achieved by laser or sandblasting (Gundogdu et al., 2014). Water bath denture base materials are the most widely used denture bases, despite having certain disadvantages such as containing residual monomers. These monomers can have negative effects on the physical and mechanical properties of the denture and can cause porosity, grazing, and warpages. The monomer can be negatively being affected in conventional water bath acrylic due to the time and heat (Figueroa et al., 2018). Various researchers have investigated the efficiency of microwave irradiation and reported it to be simpler, faster and safer, and cleaner (Ozkir et al., 2018). Such methods were first suggested by Nishii in 1968 as an alternative PMMA processing approach and have since become widely popular compared to conventional water-bath approaches. Nishi and colleagues published their first reports on radiation exposure with microwave in 1984 and 1985, where they 
used perforated metal flask and heat transfer to the acrylic resin (Barbosa et al., 2002). Since then, the fiberreinforced flask (FRP) became widespread as part of the microwave ovens where it's being employed to avoid using metal flasks to achieve microwave irradiation (Singh et al., 2013). Use of microwave heating has certain advantages as well, compared to conventional curing methods. With microwave heating, the inner and outer surfaces of the sample are heated to almost exactly the same temperature level and the temperature increases rapidly (Skinner and Phillips, 1982). This study was performed to compare the effects of conventional water bath/microwave curing techniques of PMMA and soft liner on the shear bond strength (SBS) between soft liner materials and PMMA and to investigate methods to improve the SBS value between these materials.

\section{MATERIALS AND METHODS}

\section{Description of Study Sample}

Each sample used as part of the study consists of 2 PMMA strips with dimensions $50 \times 10 \times 3 \mathrm{~mm}$ (length, width, and thickness, respectively). Both acrylic PMMA strips for each sample were attached to the square section of soft liner which is $10 \times 10 \times 3 \mathrm{~mm}$ in size (length, width, and thickness respectively) (Salloum, 2013; Salloum, 2014) as shown in the following diagram [Figure 1]. Using an overlap-joint model, 80 study samples were then separated into eight groups, where each group was consisted of ten samples, according to the polymerization and preparation types. These groups are as below:

Group 1 (ALWW): Lased water bath cured PMMA with water bath cured soft liner, Group 2 (ASWW): Sandblasted water bath cured PMMA with water bath cured soft liner, Group 3 (ALWM): Lased water bath cured PMMA with microwave cured soft liner, Group 4 (ASWM): Sandblasted water bath cured PMMA with microwave cured soft liner, Group 5 (BLMW): Lased microwave cured PMMA with water bath cured soft liner, Group 6 (BSMW): Sandblasted microwave cured PMMA with water bath cures soft liner, Group 7 (BLMM): Lased microwave cured PMMA with microwave cured soft liner finally, Group 8 (BSMM): Sandblasted microwave cured PMMA with microwave cured soft liner. The PMMA strips (used denture base material)

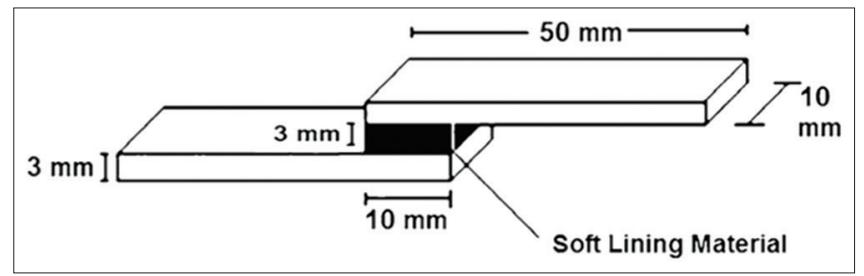

Figure 1: Shear bond strength study sample (Salloum, 2014) used in this study represent two different curing techniques. A total of 160 PMMA strips were crafted using a milling machine, from a metal master plate. Each strip has the dimensions of $50 \times 10 \times 3 \mathrm{~mm}$ (length, width, and thickness, respectively) (Salloum, 2013; Salloum, 2014). Two layers of wax sheet were fixed together and cut along with the metal plate in the same dimensions. A total of 80 wax patterns were prepared for flasking process of the conventional water bath group. The wax patterns were invested in the metal flask and placed in water bath for $4 \mathrm{~min}$ at $100^{\circ} \mathrm{C}$ (Anusavice, 1996). Once the wax was eliminated, the dough-mass of the conventional water bath (Ivoclar triplex, Liechtenstein) PMMA was packed and cured in water bath for $45 \mathrm{~min}$ at $100^{\circ} \mathrm{C}$, as shown in Figure 2, following manufacturer instructions. For the preparation of microwave PMMA strips, another 80 units of wax patterns were prepared for flasking. The wax patterns were invested in FRP (GC, Tokyo 174-8585, Japan and placed in a domestic microwave oven (Panasonic, 2003, nn-g $\times 36 \mathrm{wf}$, Japan) for $1 \mathrm{~min}$ on 500 watts, as suggested by the manufacturer. Once the wax was eliminated, the dough-mass of PMMA (Nature-Cryl, Acron Gc, Japan) was packed and cured in domestic microwave for 3 min on 500 watts, as instructed by the manufacturer [Figure 3]. The surfaces of a total of 160 PMMA strips were then prepared before application of the soft liner, specifically at the area that will be attached to the soft liner for each strip in a $10 \times 10 \mathrm{~mm}$ area. This was performed by placing a plastic sticker with a window attached to the PMMA strip from the surface of each two PMMA strips that will be attached later to the soft liner. 80 PMMA strips were then irradiated with hard tissue laser neodymium:yttriumaluminum-garnet (Q-switched Nd:YAG) with $1064 \mathrm{~nm}$ wave length and $57.3 \mathrm{j} / \mathrm{cm}^{2}$ fluence and $1800 \mathrm{mj}$ energy with $1 \mathrm{HZ}$ frequency (Korkmaz et al., 2013).

[Figures 4 and 5] The remaining 80 PMMA strips were sandblasted with $\mathrm{AL}_{2} \mathrm{O}_{3}(250 \mu \mathrm{m})$ for $1 \mathrm{~min}$ (Aziz, 2017).

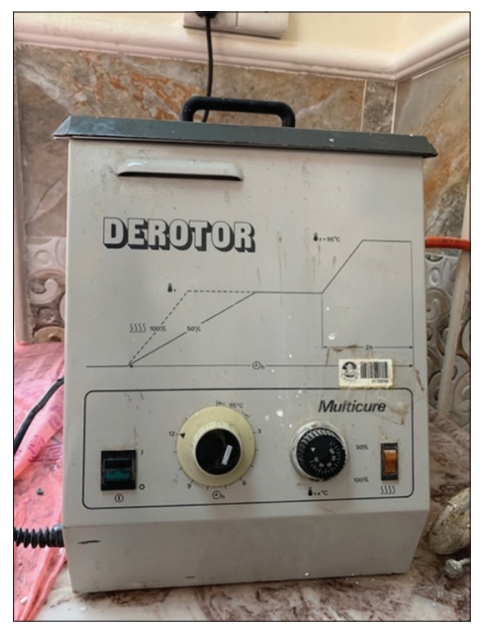

Figure 2: Water bath for polymerizing PMMA water bath cured samples and soft liner 


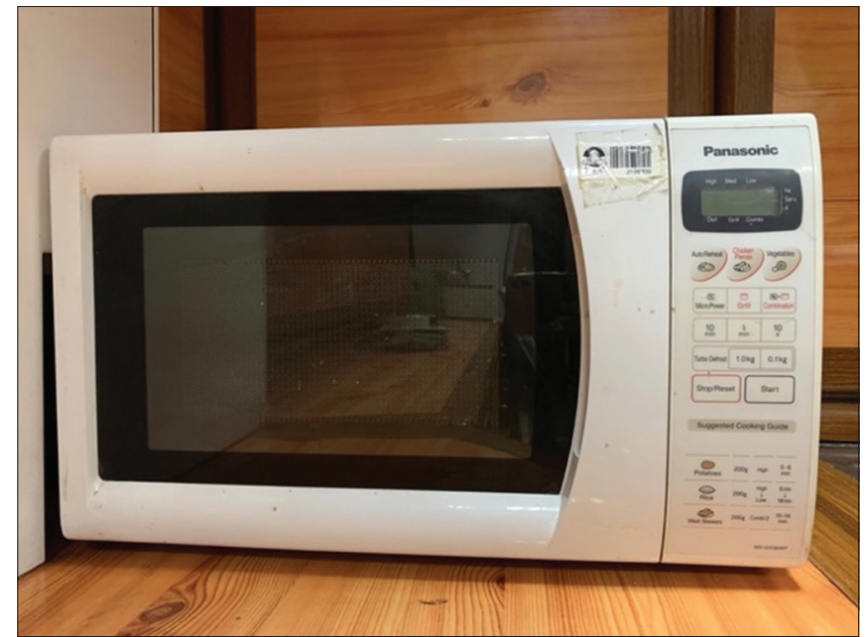

Figure 3: Domestic microwave for polymerizing PMMA microwave cured samples and soft liner

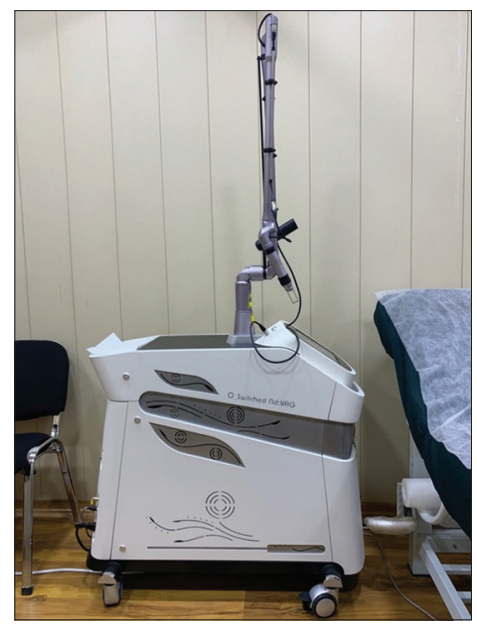

Figure 4: Q switched Nd:YAG device used for PMMA surface treatment

The PMMA strips were then applied with the dental stone (SYNA ROCK, Germany), together with glass spacers with dimensions of $10 \times 10 \times 3 \mathrm{~mm}$ (length, width, and thickness, respectively) to provide space for the soft liner materials after their removal. Primo adhesive (DETAX, Germany) was then applied to the PMMA bond surface before the application of the soft liner material Molloplast B (DETAX, Germany) on the treated surfaces (by laser or sandblasting). For conventional water bath polymerization, the soft lining liner materials were packed between two PMMA strips in metal flask and then placed in water bath for $2 \mathrm{~h}$ on $100^{\circ} \mathrm{C}$. For microwave polymerization, the soft liner material was packed between two PMMA strips inside the FRP flask and was then placed in the microwave for 10 min on 850 watt power, following the manufacturer's instructions. As shown in Figure 6 to pack and cure the soft liners, samples were maintained in distal water $37 \pm$ for $24 \mathrm{~h}$ (Al-Athel et al., 2002).

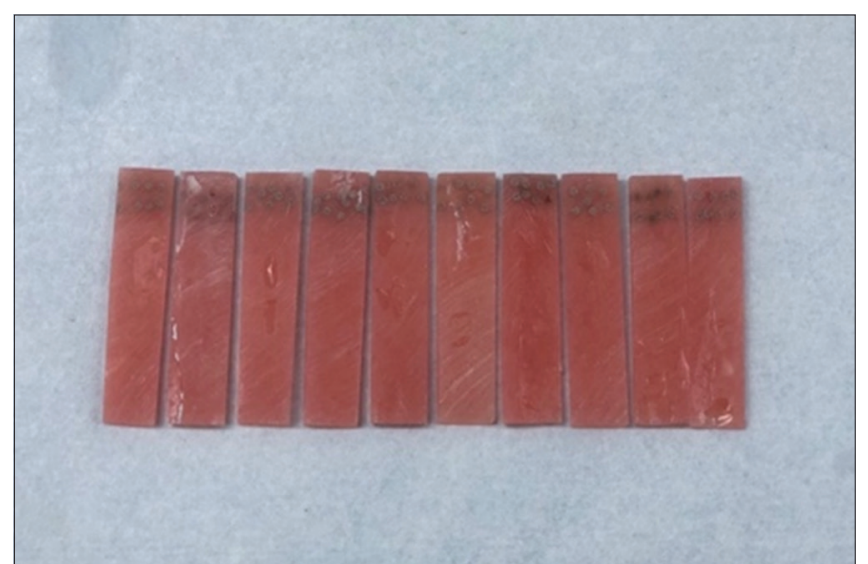

Figure 5: PMMA samples surface after being irradiated by Q-switched Nd:YAG

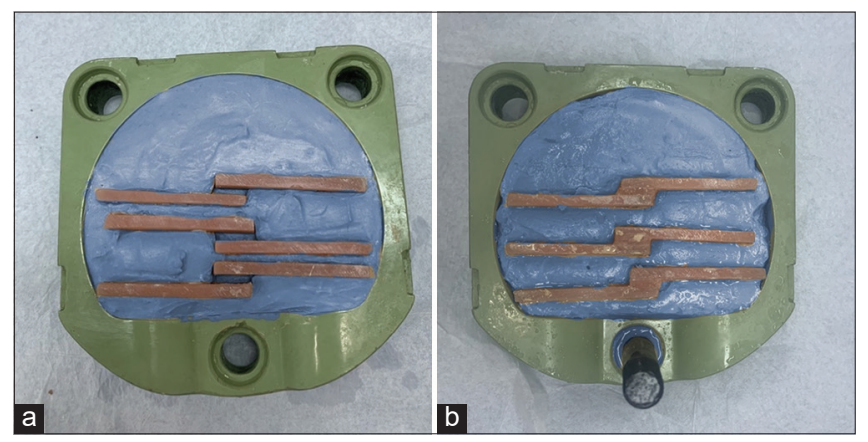

Figure 6: (a) Before packing the soft liner, (b) After packing the soft liner

To measure the SBS values for the samples at cross head speed of $40 \mathrm{~mm} / \mathrm{min}$, samples were placed in a motorized testing machine (Digital force, gauge, IMADA Co, LTD, Japan) vertically grasped by the two sides of the machine, as shown in Figures 7 and 8 (Salloum, 2013), and the highest force levels applied where point of failure was reached and the surfaces separated was recorded. These records were in kilogram units and were later converted to Mega Pascal $(\mathrm{MPa})$ using the following equation $\mathrm{MPa}=$ maximum load $\mathrm{kg} /$ cross-sectional area $\mathrm{cm}^{2}$ (Salloum, 2014).

In the present study, the surface area was $1 \times 1 \mathrm{~cm}$, and therefore the below equation was Valid:MPA=KG/ SURFACE AREA.

\section{RESULTS}

In the present study, the effects of three different variables (PMMA conventional water bath and microwave curing technique, soft liner water-bath and microwave curing technique, and surface treatment by laser or sandblasting) on the SBS values between Molloplast B soft liner and PMMA material were evaluated. The mean SBS values were recorded in $\mathrm{MPa}$ and the standard deviation of 80 PMMA 


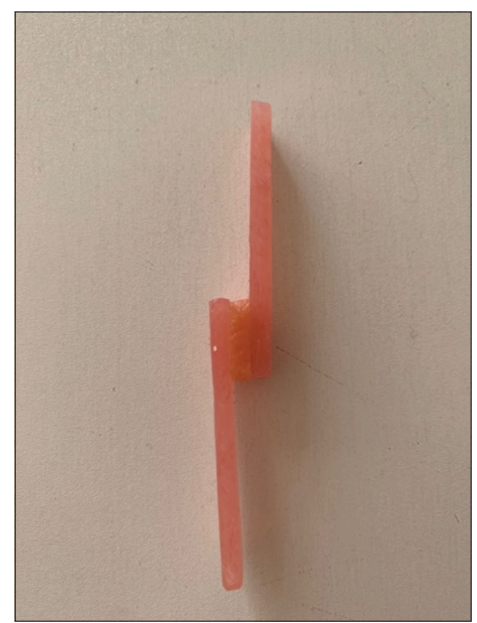

Figure 7: SBS sample

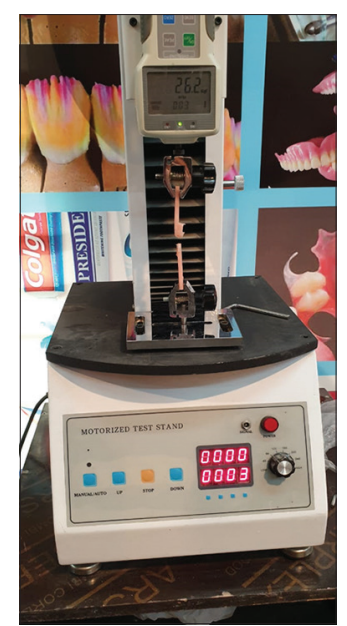

Figure 8: SBS by motorized testing machine

samples cured by conventional water bath and microwave techniques are listed in Table 1. Highest SBS was achieved in Group 1 (ALWW): Lased water bath cured PMMA with water bath cured soft liner, and the SBS value was $28.81 \pm$ 6.40. The lowest SBS was observed in Group 8 (BSMM): Sandblasted microwave cured PMMA with microwave cured soft liner with $10.57 \pm 1.57$, as shown in Table 1 . Only the curing technique of soft liner showed significant difference in terms of SBS value between Molloplast B and PMMA [Table 2]. The curing techniques of conventional (water bath + microwave) and surface treatment methods with laser and sandblasting for PMMA did not have any statistically significant effects on the SBSs value between Molloplast B and PMMA [Tables 3 and 4].

To evaluate the level of the interaction between the tested variables, analysis of variance (ANOVA) and post hoc (LSD) tests were performed. The analysis shows that there are statistically significant differences in terms of SBS $(P<0.001)$ for the interaction between the surface treatment and the curing techniques of soft liner and
Table 1: Means of shear bond strength of the study groups

\begin{tabular}{lcccc}
\hline Groups & $\boldsymbol{n}$ & $\begin{array}{c}\text { Mean shear bond } \\
\text { strength }(\mathrm{MPa})\end{array}$ & $( \pm \mathrm{SD})$ & $\boldsymbol{P}$ (ANOVA) \\
\hline G1: ALWW & 10 & 28.81 & $( \pm 6.40)$ & \\
G2: ASWW & 10 & 23.49 & $( \pm 7.41)$ & \\
G3: ALWM & 10 & 18.07 & $( \pm 3.74)$ & \\
G4: ASWM & 10 & 19.83 & $( \pm 3.26)$ & $<0.001$ \\
G5: BLMW & 10 & 27.63 & $( \pm 5.88)$ & \\
G6: BSMW & 10 & 26.84 & $( \pm 4.48)$ & \\
G7: BLMM & 10 & 12.42 & $( \pm 2.84)$ & \\
G8: BSMM & 10 & 10.57 & $( \pm 1.57)$ & \\
Total & 80 & 20.96 & $( \pm 7.99)$ & \\
\hline
\end{tabular}

Table 2: Mean of shear bond strength by polymerization of soft liner

\begin{tabular}{lcccc}
\hline $\begin{array}{l}\text { Polymerization of } \\
\text { soft liner }\end{array}$ & $\boldsymbol{n}$ & $\begin{array}{c}\text { Mean shear bond } \\
\text { strength }(\mathrm{MPa})\end{array}$ & $( \pm \mathrm{SD})$ & $\boldsymbol{P}$ \\
\hline Water bath cured & 40 & 26.69 & $( \pm 6.23)$ & $<0.001$ \\
Microwave cured & 40 & 15.22 & $( \pm 4.82)$ & \\
\hline
\end{tabular}

Table 3: Mean of shear bond strength by type of polymerization of PMMA

\begin{tabular}{lcccc}
\hline Variables & $\boldsymbol{n}$ & $\begin{array}{c}\text { Mean shear bond } \\
\text { strength }(\mathrm{MPa})\end{array}$ & $( \pm \mathrm{SD})$ & $\boldsymbol{P}^{\star}$ \\
\hline \multicolumn{4}{l}{ Polymerization of PMMA } \\
Water bath & 40 & 22.55 & $( \pm 6.72)$ & 0.075 \\
Microwave & 40 & 19.37 & $( \pm 8.89)$ & \\
\hline
\end{tabular}

Table 4: Mean of shear bond strength by method of surface treatment of PMMA

\begin{tabular}{lcccc}
$\begin{array}{l}\text { Roughening of } \\
\text { acrylic surface }\end{array}$ & $\boldsymbol{n}$ & $\begin{array}{c}\text { Mean shear bond } \\
\text { strength }(\mathrm{MPa})\end{array}$ & $( \pm \mathrm{SD})$ & $\boldsymbol{P}$ \\
\hline Laser & 40 & 21.73 & $( \pm 8.36)$ & 0.389 \\
Sandblasting & 40 & 20.18 & $( \pm 7.63)$ & \\
\hline
\end{tabular}

PMMA. Table 5 shows these differences (based on the ANOVA test) between and within the study groups regarding the mean SBS $(P<0.001)$. The post hoc LSD evaluation revealed significant differences between $G 1$ with the other groups, except for G5 and G6. The differences between the mean SBS of G2 and the other groups were all significant except for G4, G5, and G6. All the differences between $\mathrm{G} 3$ and the other groups were significant as well, except for G4. Group 5 had significant differences with G3, G4, G7, and G8. G6 had significant differences with G3, G4, G7, and G8. G7 had significant differences with all the groups except for G8. Finally, G8 had significant differences with all the groups except for G7.

\section{DISCUSSION}

In the present study, the highest mean value of shear bond failure was recorded in G1 (lased water bath cured PMMA with and water bath cured soft liner), which was $28.8 \mathrm{MPa}$ and lowest mean of shear bond failure was recoded in G8 
Table 5: $P$ values obtained by the post hoc test (LSD)

\begin{tabular}{lcccccrrr} 
Groups & G1 & G2 & G3 & G4 & G5 & G6 & G7 & G8 \\
G1 & & 0.016 & $<0.001$ & $<0.001$ & 0.586 & 0.364 & $<0.001$ & $<0.001$ \\
G2 & & 0.014 & 0.094 & 0.059 & 0.124 & $<0.001$ & $<0.001$ \\
G3 & & & 0.417 & $<0.001$ & $<0.001$ & 0.011 & 0.001 \\
G4 & & & & 0.001 & 0.002 & 0.001 & $<0.001$ \\
G5 & & & & 0.715 & $<0.001$ & $<0.001$ \\
G6 & & & & & & $<0.001$ & $<0.001$ \\
G7 & & & & & & & \\
\hline
\end{tabular}

(sandblasted microwave cured PMMA with microwave cured soft liner) which was $10.57 \mathrm{MPa}$ as shown in Table 1. Regarding the effect of PMMA curing technique, the mean SBS of samples cured by conventional water bath technique $(22.5 \pm 6.72 \mathrm{MPa})$ was higher than mean SBS of samples cured by microwave technique (19.37 $\pm 8.89 \mathrm{MPa})$, but the difference was not statistically significant. The results summarized in Table 3 are also supported by the studies of (Jagger, 1978), (Ozkir et al., 2018), (Consani et al., 2016). Some conflicting studies claim that microwave method achieved higher bond strength and longevity with PMMA, (Barbosa et al., 2007; Ng et al., 2004; Geerts and Jooste, 1993) while others claim that the conventional water bathcured PMMA shows better clinical characteristics and bond strength due to having less residual monomer and porosity compared to the microwave cured PMMA (Lai et al., 2004). Regarding the effects of soft liner curing technique, the results of this study show that SBS of conventional water bath cured soft liner $(26.69 \pm 6.23 \mathrm{MPa})$ was significantly higher than microwave cured soft liner $(15.22 \pm 4.82 \mathrm{MPa})$ as shown in Table 2. These results are supported by the previous studies (Aydin et al., 1999; Clancy et al., 1991; Arena et al., 1993). Some studies disagree, and have shown that the soft liner cured by microwave achieved higher bond strength (Usumez et al., 2004; Amin et al., 1981) since microwave irradiation is affected by the benzoyl peroxide. The duration and magnitude of the exothermic reaction vary due to the fact that the higher the power the higher the temperature is achieved, and the faster the benzoyl peroxide decomposes and polymerization reaction starts. The process then continues until all monomers are converted. Microwave exothermic response is instantaneous, on the other hand, and raising the temperature of the resin quicker and to higher levels compared to that of the conventional water bath technique (Lai et al., 2004). The effects of different surface treatment methods on SBS were also investigated in this study, and the results indicate that the SBS of lased PMMA $(22.73 \pm 8.36 \mathrm{MPa})$ was higher than the SBS of sandblasted PMMA (20.18 $\pm 7.63 \mathrm{MPa})$, but the difference was not statistically significant, as shown in Table 4. These results were supported by the study of Usumez et al. (2004). Explanation for this could be that the high energy pulse of laser has a strong impact, which may result in an instantaneous evaporation of water from the bath-cured
PMMA, which, in turn, leads to a significant expansion in volume. Such an expansion in quick succession may turn cause the material around the reaction area to suddenly ablate and might increase the surface area of the PMMA surface due to the emergent roughness. This would mean that the soft liner materials adhere into the uneven surfaces or pits created by the laser application, and increase the SBS value in the end (Aziz, 2017). Further research and investigation suggested the $\mathrm{Nd}$ :YAG laser system, that is why the $\mathrm{Nd}$ :YAG has been chosen in the present study (Usumez et al., 2004). Regarding the sandblasted PMMA, on the other hand, the results were are in line with the findings of Jacobson, who concluded that roughening of the PMMA before the soft liner application could have a negative effect on the bond of the PMMA denture base (Amin et al., 1981). Explanation for, that is, during the roughening of the surface of the PMMA, a certain degree of stress is imposed to the junction of the PMMA and the soft liner material surface, which reduces the bond strength. Another reason for that might be that the roughening of the surface does not create irregularities that are sufficient in magnitude as the laser can, and therefore the soft liner cannot flow into it as efficiently (Jacobsen et al., 1997). Other conflicting studies have shown that sandblasting the acrylic resin surface before placing a resilient lining material can create a moderately irregular surface, provided that the mechanical locking for the soft material can be achieved, which, in turn, causes an increase in the strength of the bond (Khanna et al., 2015).

\section{CONCLUSION}

Within the limitation of this study, the conventional water bath-cured soft liner has been shown to improve the SBS between the soft liner and the PMMA denture base material, while the other factors the such as the PMMA curing techniques and/or the surface treatment of PMMA has not influenced SBS between the soft liner and the PMMA denture base material significantly.

\section{ACKNOWLEGMENT}

The authors would like to thank DR.Rebuar Fadhil for helping to provide the microwave acrylic resin and the FRP. 


\section{REFERENCES}

Akin, H., F. Tugut, U. Guney, O. Kirmali and T. Akar. 2013. Tensile bond strength of silicone-based soft denture liner to two chemically different denture base resins after various surface treatments. Lasers Med. Sci. 28(1): 119-123.

Al-Athel, M., R. Jagger and D. Jagger. 2002. Effect of ageing on the bond strength of a permanent denture soft lining material. J. Oral Rehabil. 29(10): 992-996.

Amin, W., A. Fletcher and G. Ritchie. 1981. The nature of the interface between polymethyl methacrylate denture base materials and soft lining materials. J. Dent. 9(4): 336-346.

Anusavice, K. J. A. 1996. Philip's Science of Dental Materials. WB Saunders Co., Philadelphia, PA.

Arena, C. A., D. B. Evans and T. J. Hilton. 1993. A comparison of bond strengths among chairside hard reline materials. J Prosthet. Dent. 70: 126-131.

Aydın, A., H. Terzioğlu, A. Akınay, K. Ulubayram and N. Hasirci. 1999. Bond strength and failure analysis of lining materials to denture resin. Dent. Mater. 15(3): 211-218.

Aziz, H. K. 2017. Effect of the $\mathrm{CO}_{2}$ laser as surface treatment on the bond strength of heat cured soft liner to the high impact acrylic denture base material. J. Baghdad Coll. Dent. 29(1): 20-26.

Barbosa, D. B., M. Compagnoni and C. Leles. 2002. Changes in occlusal vertical dimension in microwave processing of complete dentures. Braz. Dent. J. 13(3): 197-200.

Barbosa, D. B., R. F. D. Souza, A. C. Pero, J. Marra and M. A. Compagnoni. 2007. Flexural strength of acrylic resins polymerized by different cycles. J. Appl. Oral Sci. 15(5): 424428.

Clancy, J. M., L. F. Hawkins, J. C. Keller and D. B. Boyer. 1991. Bond strength and failure analysis of light-cured denture resins bonded to denture teeth. J. Prosthet. Dent. 65(2): 315-324.

Consani, R. L. X., B. L. Folli, M. C. Nogueira, A. B. Correr and M. F. Mesquita. 2016. Effect of polymerization cycles on gloss, roughness, hardness and impact strength of acrylic resins. Braz. Dent. J. 27(2): 176-180.

Figueroa, R. M. S., B. Conterno, C. A. G. Arrais, C. Y. C. Sugio, V. M. Urban and K. H. Neppelenbroek. 2018. Porosity, water sorption and solubility of denture base acrylic resins polymerized conventionally or in microwave. J. Appl. Oral Sci. 26: e20170383.

Geerts, G. A. and C. H. Jooste. 1993. A comparison of the bond strengths of microwave-and water bath-cured denture material. J. Prosthet. Dent. 70(5): 406-409.

Gundogdu, M., Z. Y. Duymus and M. Alkurt. 2014. Effect of surface treatments on the bond strength of soft denture lining materials to an acrylic resin denture base. J. Prosthet. Dent. 112(4): 964-971.

Jacobsen, N. L., D. L. Mitchell, D. L. Johnson and R. A. Holt. 1997.
Lased and sandblasted denture base surface preparations affecting resilient liner bonding. J. Prosthet. Dent. 78(2): 153-158.

Jagger, R. 1978. Effect of the curing cycle on some properties of a polymethylmethacrylate denture base material. J. Oral Rehabil. 5: 151-157.

Khanna, A., V. M. Bhatnagar, K. T. Karani, K. Madria and S. Mistry. 2015. A comparative evaluation of shear bond strength between two commercially available heat cured resilient liners and denture base resin with different surface treatments. J. Clin. Diagn. Res. 9(5): 30-34.

Korkmaz, F. M., B. Bagis, M. Özcan, R. Durkan, S. Turgut and S. M. Ates. 2013. Peel strength of denture liner to PMMA and polyamide: laser versus air-abrasion. J. Adv. Prosthodont. 5(3): 287-295.

Lai, C. P., M. H. Tsai, M. Chen, H. S. Chang and H. H. Tay. 2004. Morphology and properties of denture acrylic resins cured by microwave energy and conventional water bath. Dent. Mater. 20(2): 133-141.

Ng, E. T. L., B. Chew and H. Thean. 2004. Shear bond strength of microwaveable acrylic resin for denture repair. J. Oral Rehabil. 31(8): 798-802.

Ozkir, S. E., B. Yilmaz, S. M. Unal, A. Culhaoglu and I. Kurkcuoglu. 2018. Effect of heat polymerization conditions and microwave on the flexural strength of polymethyl methacrylate. Eur. J. Dent. 12(1): 116.

Salloum, A. M. 2013. Shear bond strength of three silicone lining materials bonded to heat-cured denture resin. King Saud Univ. J. Dent. Sci. 4(1): 17-20.

Salloum, A. M. 2014. Effect of aging on bond strength of two soft lining materials to a denture base polymer. J. Indian Prosthodont. Soc. 14(1): 155-160.

Sauer, J. L. 1966. A clinical evaluation of Silastic 390 as a lining material for dentures. J. Prosthet. Dent. 16(4): 650-660.

Singh, S., J. N. Palaskar and S. Mittal. 2013. Comparative evaluation of surface porosities in conventional heat polymerized acrylic resin cured by water bath and microwave energy with microwavable acrylic resin cured by microwave energy. Contemp. Clin. Dent. 4(2): 147-51.

Skinner, E. W. and R. W. Phillips. 1982. Skinner's Science of Dental Materials. $8^{\text {th }}$ ed. WB Saunders Company, Philadelphia, Pennsylvania, PA.

Tata, S. and D. Nandeeshwar. 2012. A clinical study to evaluate and compare the masticatory performance in complete denture wearers with and without soft liners. J. Contemp. Dent. Pract. 13(6): 787-792.

Usumez, A., O. Inan and F. Aykent. 2004. Bond strength of a silicone lining material to alumina-abraded and lased denture resin. J. Biomed. Mater. Res. Part B. 71(1): 196-200. 